\title{
IL13 genetic polymorphisms, smoking, and eczema in women: a case-control study in Japan
}

Yoshihiro Miyake ${ }^{1 *}, K_{\text {Keiko Tanaka }}{ }^{\text {and Masashi }}$ Arakawa $^{2}$

\begin{abstract}
Background: Several genetic association studies have examined the relationships between single nucleotide polymorphisms (SNPs) in the IL13 gene and eczema, and have provided contradictory results. We investigated the relationship between the IL13 SNPs rs1800925 and rs20541 and the risk of eczema in Japanese young adult women.

Methods: Included were 188 cases who met the criteria of the International Study of Asthma and Allergies in Childhood (ISAAC) for eczema. Control subjects were 1,082 women without eczema according to the ISAAC criteria, who had not been diagnosed with atopic eczema by a doctor and who had no current asthma as defined by the European Community Respiratory Health Survey criteria. Adjustment was made for age, region of residence, number of children, smoking, and education.

Results: The minor TT genotype of SNP rs1800925 was significantly associated with an increased risk of eczema in the co-dominant model: the adjusted odds ratio was 2.19 (95\% confidence interval: 1.03-4.67). SNP rs20541 was not related to eczema. None of the haplotypes were significantly associated with eczema. Compared with women with the CC or CT genotype of SNP rs 1800925 who had never smoked, those with the TT genotype who had ever smoked had a 2.85 -fold increased risk of eczema, though the adjusted odds ratio was not statistically significant, and neither multiplicative nor additive interaction was statistically significant.
\end{abstract}

Conclusions: Our findings suggest that the IL13 SNP rs1800925 is significantly associated with eczema in Japanese young adult women. We could not find evidence for an interaction between SNP rs1800925 and smoking with regard to eczema.

\section{Background}

In Japan, atopic eczema is a major public health problem not only among children but also among adults. One study has reported atopic eczema prevalence values of $10.9 \%$ and $7.8 \%$ among Japanese women in their $20 \mathrm{~s}$ and 30s, respectively [1]. The role of genetic and environmental risk factors in the development of atopic eczema has gained interest.

Interleukin (IL)-13 is a central mediator of Th2 immune responses [2]. IL-13 is expressed in acute and chronic lesions and in unaffected skin from patients with atopic eczema [3]. T cells and mast cells are important sources of IL-13 in skin lesions from patients with atopic eczema [4]. The percentage of $\mathrm{CD} 4^{+} \mathrm{IL}-13^{+} \mathrm{T}$ cells has been shown to

\footnotetext{
* Correspondence: miyake-y@fukuoka-u.ac.jp

'Department of Preventive Medicine and Public Health, Faculty of Medicine, Fukuoka University, Fukuoka, Japan

Full list of author information is available at the end of the article
}

correlate significantly with the severity of atopic eczema in children [5]. High IL-13 production by phytohaemagglutinin- and house dust mite allergen Der p 1-stimulated cord blood mononuclear cells has been associated with the development of atopic eczema by the age of 3 years [6].

Several genetic association studies have examined relationships between single nucleotide polymorphisms (SNPs) in the IL13 gene and eczema, and have provided contradictory results [7-15]. Our recent study of Japanese children aged 3 years showed that the minor TT genotype of SNP rs1800925 $(-1024 \mathrm{C} / \mathrm{T})$ and the minor AA genotype of SNP rs20541 (Arg110/130Glu) were significantly related to an increased risk of eczema and that perinatal smoking exposure did not interact with the 2 SNPs in the etiology of eczema [15]. These 2 SNPs are functional SNPs. Having established this, we wished to investigate these issues in Japanese adults using data
C Biomed Central 
from the Kyushu Okinawa Maternal and Child Health Study (KOMCHS).

\section{Methods Study Population}

The KOMCHS is an ongoing prospective prebirth cohort study that investigates risk and preventive factors for maternal and child health problems such as allergic disorders. From April 2007 to March 2008, the KOMCHS requested that 131 obstetric hospitals in Fukuoka Prefecture, the largest prefecture on Kyushu Island in southern Japan, with a total population of approximately 5.04 million, provide as many pregnant women as possible with a set of leaflets explaining the KOMCHS, an application to participate in the study, and a self-addressed stamped envelope in which to return the application. From May 2007 to March 2008, the KOMCHS also requested that 40 obstetric hospitals in Okinawa Prefecture, one of the southernmost islands of Japan, with a total population of almost 1.37 million, provide as many pregnant women as possible with a comparable set of documents. Later, to increase the sample size, pregnant women living in 6 prefectures on Kyushu Island other than Fukuoka Prefecture, with a total population of approximately 8.22 million, were provided with comparable documents at 252 obstetric hospitals between August 2007 and March 2008. Pregnant women who intended to participate in the KOMCHS returned the application form to the data management center. By the end of the study, a total of 1757 pregnant women between the 5th and 39th week of pregnancy had given their fully informed consent in writing to participate in the KOMCHS and had completed the baseline survey. Around four months after delivery, 1492 women gave informed consent to genotyping. The ethics committee of the Faculty of Medicine, Fukuoka University, approved the KOMCHS.

\section{Selection of Cases and Controls}

Women with eczema were identified based on the International Study of Asthma and Allergies in Childhood (ISAAC) Phase One questionnaire [16]. Affirmative answers to the following 3 questions were required: 'Have you ever had an itchy rash which was coming and going for at least 6 months?', 'Have you had this itchy rash at any time in the last 12 months?' and 'Has this itchy rash at any time affected any of the following places: the folds of the elbows, behind the knees, in front of the ankles, under the buttocks, or around the neck, ears, or eyes?' Eventually, 188 cases of eczema were identified.

Of the 1304 remaining participants who were therefore eligible to serve as controls, 173 women were excluded from the analysis because they answered 'yes' to the question: 'Have you ever been diagnosed by a physician as having atopic eczema?'. Sixty-six were excluded who provided a positive response to either of 2 situations: an asthma attack during the last 12 months or current use of asthma medication, with asthma as defined by the European Community Respiratory Health Survey [17]. Finally, 1 mother was excluded because of missing data on smoking. Because 18 mothers had both doctor-diagnosed atopic eczema and current asthma, 1082 control subjects remained for the final analysis.

\section{DNA Extraction and Genotyping}

Research technicians or subjects themselves collected buccal specimens with BuccalAmp swabs (Epicenter BioTechnologies, Madison, WI, USA). Genomic DNA was extracted using a QIAmp DNA mini kit (Qiagen, Inc., Valencia, CA, USA). Two SNPs from the IL13 gene were used in this study: rs1800925 in the 5' promoter region and rs20541 in exon 4. Genotyping of the two IL13 polymorphisms was performed using pre-development TaqMan SNP Genotyping Assays (Applied Biosystems, Foster City, CA, USA).

\section{Statistical Analysis}

Deviation from the Hardy-Weinberg equilibrium among control subjects was evaluated by the chi-square test. Linkage disequilibrium was investigated using Haploview software version 4.1 [18]. Logistic regression analysis was used to obtain the crude odds ratios (ORs) and $95 \%$ confidence intervals (CIs) for eczema relative to the SNPs under study. Multiple logistic regression analysis was used to adjust for age, region of residence, number of children, smoking, and education. The statistical power calculation was performed using QUANTO version 1.2 [19]. Haplotypes and their frequencies were inferred with the expectation maximization (EM) algorithm. For differences in haplotype frequency between the case and control groups, crude ORs and 95\% CIs were estimated based on the frequency of each haplotype relative to all other haplotypes combined. The multiplicative interaction was tested using a term of the product of two variables in a multiple logistic regression model. Three measures were used to test the additive interaction [20]: 1) relative excess risk due to interaction (RERI), 2) attributable proportion due to interaction (AP), and 3) synergy index (S). RERI is the excess risk due to an interaction relative to the risk without exposure. AP refers to the attributable proportion of disease that is due to an interaction among individuals with both exposures. $\mathrm{S}$ is the excess risk from both exposures when there is an additive interaction, relative to the risk from both exposures without an interaction. $\mathrm{RERI}=0, \mathrm{AP}=0$, or $\mathrm{S}=1$ means no interaction or strict additivity; RERI > 0 , AP $>0$, or $\mathrm{S}>1$ means positive interaction or more than additivity; RERI $<0, \mathrm{AP}<0$, or $\mathrm{S}<1$ means negative interaction or less than additivity [21]. If any of the null values (0 in RERI and AP or 1 in S) falls outside the 95\% 
$\mathrm{CI}$ of its respective measurement, then the additive interaction is considered statistically significant. Details of the method for the calculation of the additive interaction have been described by Andersson et al. [20]. Excluding the calculation of linkage disequilibrium and statistical power calculation, all statistical analyses were performed using STATA/SE software version 12.0 (StataCorp, College Station, TX, USA).

\section{Results}

Compared with control subjects, women with eczema were more likely to be younger (Table 1). There were no differences between eczema cases and control subjects with regard to region of residence, number of children, smoking, and education.

IL13 SNPs rs1800925 and rs20541 were tested for deviation from the Hardy-Weinberg equilibrium; there was no deviation among control subjects $(\mathrm{p}=0.10$ and 0.83 , respectively). SNPs rs1800925 and rs20541 were in high linkage disequilibrium $\left(D^{\prime}=0.84, r^{2}=0.37\right)$.

The frequency of the TT genotype of SNP rs1800925 was $5.3 \%$ in cases and $2.5 \%$ in control subjects (Table 2). Compared to a reference group of subjects with the CC genotype, women with the TT genotype had a significantly increased risk of eczema, whereas no association was found between the CT genotype and eczema in crude analysis. Adjustment for confounders under investigation did not appreciably change the results: the adjusted ORs for the CT and TT genotypes were 1.01 (95\% CI: 0.71-1.42) and 2.19 (95\% CI: 1.03-4.67), respectively. In the recessive model, the TT genotype was significantly positively associated with eczema: the adjusted OR was 2.19 (95\% CI: 1.04-4.63); however, no significant relationship was observed in the additive or dominant model. We could not find a significant association between SNP rs20541 and eczema in any genetic model.
With respect to SNP rs20541, the statistical power calculation revealed that, using our sample size, we could detect the gene-disease association for an OR of 1.397 with an accuracy of more than $80 \%$ under the log-additive model.

Four haplotypes were constructed, but none of these were significantly associated with the risk of eczema (Table 3).

Compared with women with the $\mathrm{CC}$ or $\mathrm{CT}$ genotype of SNP rs1800925 who had never smoked, those with the TT genotype who had ever smoked had a 2.85 -fold increased risk of eczema, although the adjusted OR was not statistically significant, and neither multiplicative nor additive interaction was statistically significant (Table 4).

The results of a sensitivity analysis restricted to cases without current asthma as defined by the European Community Respiratory Health Survey $(\mathrm{n}=165)$ were similar to those in the overall analysis: the adjusted OR was 2.51 (95\% CI: 1.18-5.36) for the TT genotype of SNP rs1800925 and 1.33 (95\% CI: 0.75-2.36) for the AA genotype of SNP rs20541 in the co-dominant model.

\section{Discussion}

Our previous study of Japanese children aged 3 years observed that both IL13 SNPs rs1800925 and rs20541 were significantly associated with the risk of eczema [15]. Interestingly, in that study, after mutual adjustment for SNPs rs1800925 and rs20541, the positive relationship between SNP rs1800925 and eczema remained statistically significant, whereas the positive association between SNP rs20541 and eczema completely disappeared [15]. The current results are in partial agreement with our previous findings. Another Japanese case-control study, which included patients with atopic eczema aged 11-61 years, showed a significant association between SNP

Table 1 Characteristics of the study population

\begin{tabular}{|c|c|c|c|}
\hline \multirow[b]{2}{*}{ Variable } & \multicolumn{3}{|c|}{$n(\%)$ or mean (SD) } \\
\hline & $\begin{array}{l}\text { Cases } \\
(N=188)\end{array}$ & $\begin{array}{l}\text { Controls } \\
(N=1,082)\end{array}$ & $P$ value* \\
\hline Age, years & $30.7(4.6)$ & $31.6(4.2)$ & 0.006 \\
\hline Region of residence (\%) & & & 0.50 \\
\hline Fukuoka Prefecture & $112(59.6)$ & $610(56.4)$ & \\
\hline Other than Fukuoka Prefecture in Kyushu & $61(32.5)$ & $357(33.0)$ & \\
\hline Okinawa Prefecture & $15(8.0)$ & $115(10.6)$ & \\
\hline Having one or more children (\%) & $107(56.9)$ & $669(61.8)$ & 0.20 \\
\hline Having ever smoked (\%) & $63(33.5)$ & $336(31.1)$ & 0.50 \\
\hline Education (\%) & & & 0.77 \\
\hline$<13$ years & $44(23.4)$ & $228(21.1)$ & \\
\hline $13-14$ years & $62(33.0)$ & $368(34.0)$ & \\
\hline$\geq 15$ years & 82 (43.6) & $486(44.9)$ & \\
\hline
\end{tabular}

${ }^{*} \chi^{2}$ test or $t$ test. 
Table 2 Odds ratios and 95\% confidence intervals for eczema according to IL13 polymorphisms in Japanese women

\begin{tabular}{|c|c|c|c|c|c|c|}
\hline SNP & Model & Genotype & Cases $n(\%)$ & Controls $n(\%)$ & Crude OR (95\% Cl) & Adjusted OR $(95 \% \mathrm{Cl})^{*}$ \\
\hline \multirow[t]{9}{*}{ rs1800925 } & & & $(N=188)$ & $(N=1,082)$ & & \\
\hline & Co-dominant & CC & $122(64.9)$ & $717(66.3)$ & 1.00 & 1.00 \\
\hline & & $\mathrm{CT}$ & $56(29.8)$ & $338(31.2)$ & $0.97(0.69-1.37)$ & $1.01(0.71-1.42)$ \\
\hline & & $\pi$ & $10(5.3)$ & $27(2.5)$ & $2.18(1.03-4.61)$ & $2.19(1.03-4.67)$ \\
\hline & Additive & & & & $1.15(0.87-1.52)$ & $1.18(0.89-1.56)$ \\
\hline & Dominant & CC & $122(64.9)$ & $717(66.3)$ & 1.00 & 1.00 \\
\hline & & $\mathrm{CT}+\pi$ & $66(35.1)$ & $365(33.7)$ & $1.06(0.77-1.47)$ & $1.10(0.79-1.52)$ \\
\hline & Recessive & $\mathrm{CC}+\mathrm{CT}$ & $178(94.7)$ & $1,055(97.5)$ & 1.00 & 1.00 \\
\hline & & $\pi$ & $10(5.3)$ & $27(2.5)$ & $2.20(1.04-4.61)$ & $2.19(1.04-4.63)$ \\
\hline \multirow[t]{9}{*}{ rs20541 } & & & $(N=188)$ & $(N=1,081)$ & & \\
\hline & Co-dominant & GG & $85(45.2)$ & $536(49.6)$ & 1.00 & 1.00 \\
\hline & & GA & $82(43.6)$ & $448(41.4)$ & $1.15(0.83-1.60)$ & $1.16(0.84-1.62)$ \\
\hline & & $\mathrm{AA}$ & $21(11.2)$ & $97(9.0)$ & $1.37(0.81-2.31)$ & $1.44(0.85-2.44)$ \\
\hline & Additive & & & & $1.16(0.92-1.47)$ & $1.19(0.94-1.50)$ \\
\hline & Dominant & GG & $85(45.2)$ & $536(49.6)$ & 1.00 & 1.00 \\
\hline & & $\mathrm{GA}+\mathrm{AA}$ & $103(54.8)$ & $545(50.4)$ & 1.19 (0.87-1.63) & $1.21(0.89-1.66)$ \\
\hline & Recessive & $\mathrm{GG}+\mathrm{GA}$ & 167 (88.8) & $984(91.0)$ & 1.00 & 1.00 \\
\hline & & $\mathrm{AA}$ & $21(11.2)$ & $97(9.0)$ & $1.28(0.77-2.10)$ & $1.34(0.81-2.22)$ \\
\hline
\end{tabular}

* Adjusted for age, region of residence, number of children, smoking, and education.

rs20541 and atopic eczema [8]. Of the genetic association studies conducted in countries other than Japan, to our knowledge, only 1 case-control study of Danish subjects aged 17-66 years found a significant relationship between SNP rs1800925 and atopic eczema [9]. In contrast, a null association between SNP rs1800925 and eczema was observed in studies of Canadian [10], US [11], and UK [13] children as well as in a study of children aged 8-12 years from 13 countries [14] and a study of Taiwanese young adults [12]. Two studies of German [7] and Canadian [10] children found a significant association between SNP rs20541 and eczema, whereas a relationship between SNP rs20541 and eczema was ruled out in 2 studies of US [11] and UK [13] children and in a study of Taiwanese adults [12]. These discrepancies may be at least partly explained by differences in genetic background of the populations examined, definitions of eczema, and statistical power.

In a study in the Netherlands, subjects with the TT genotype of SNP rs1800925 exhibited significantly weaker relative inhibition of IL-13 production upon additional stimulation with anti-CD2 compared to those with the CC or CT genotype [22]. Cameron and colleagues have shown that the T allele of SNP rs1800925 enhanced IL13 promoter activity in primary human and murine $\mathrm{CD} 4{ }^{+}$Th2 lymphocytes through Yin-Yang 1-dependent attenuation of STAT6-mediated promoter repression and that mitogen-activated peripheral blood mononuclear cells from pregnant women with the TT genotype of SNP rs1800925 secreted significantly higher levels of IL13 compared with those from pregnant women with the CC or CT genotype [23]. A laboratory study has shown that the IL-13 Glu110 variant is significantly more active than wild-type IL-13 in inducing STAT6 phosphorylation and CD23 expression in primary human monocytes as well as hydrocortisone-dependent IgE switching in human B cells, and that the IL-13 Glu110 variant was neutralized less effectively than wild-type IL-13 by a soluble form of IL-13R $\alpha 2$ [24].

A study in Germany reported that secondhand smoke exposure increased IL-13 levels in children with asthma [25]. In a study in the UK, a significant interaction was found between SNP rs1800925 and smoking with respect to the risk of allergy [26]. In our previous study, however,

Table 3 Haplotype analysis of rs1800925 and rs20541 in relation to eczema in Japanese women

\begin{tabular}{|c|c|c|c|c|c|}
\hline \multirow{2}{*}{$\begin{array}{l}\text { Haplotype } \\
\text { number }\end{array}$} & \multicolumn{2}{|c|}{ Haplotype structure } & \multicolumn{3}{|l|}{ Frequency $n(\%)$} \\
\hline & rs1800925 & rs20541 & Cases $(2 N=376)$ & Controls $(2 N=2,164)$ & Crude OR $(95 \% \mathrm{Cl})^{*}$ \\
\hline 1 & $C$ & $G$ & $249(66.2)$ & $1,475(68.2)$ & $0.92(0.72-1.16)$ \\
\hline 2 & C & A & $51(13.6)$ & $297(13.7)$ & $0.99(0.70-1.37)$ \\
\hline 3 & $\mathrm{~T}$ & G & $3(0.8)$ & $47(2.2)$ & $0.36(0.07-1.14)$ \\
\hline 4 & $\mathrm{~T}$ & A & $73(19.4)$ & 345 (15.9) & $1.27(0.95-1.69)$ \\
\hline
\end{tabular}

* Crude OR for each haplotype is relative to all other haplotypes combined. 
Table 4 Interaction between IL13 rs1800925 polymorphism and smoking

\begin{tabular}{|c|c|c|c|c|}
\hline \multirow[b]{3}{*}{ SNP } & \multicolumn{4}{|c|}{ Smoking status } \\
\hline & \multicolumn{2}{|c|}{ No } & \multicolumn{2}{|c|}{ Yes } \\
\hline & No. of cases/controls & Adjusted OR $(95 \% \mathrm{Cl})^{*}$ & No. of cases/controls & Adjusted OR $(95 \% \mathrm{Cl})^{*}$ \\
\hline $\mathrm{CC}+\mathrm{CT}$ & $119 / 727$ & 1.00 & $59 / 328$ & $1.06(0.75-1.50)$ \\
\hline$\pi$ & $6 / 19$ & $1.96(0.76-5.03)$ & $4 / 8$ & $2.85(0.83-9.73)$ \\
\hline \multicolumn{5}{|c|}{$P$ for multiplicative interaction $=0.69$} \\
\hline \multicolumn{5}{|c|}{ Measures of additive interaction ${ }^{+}$} \\
\hline \multicolumn{5}{|c|}{ Relative excess risk due to interaction (RERI) $=0.83$ (95\% Cl: $-3.08-4.74)$} \\
\hline \multicolumn{5}{|c|}{ Attributable proportion due to interaction (AP) $=0.29(95 \% \mathrm{Cl}:-0.78-1.37)$} \\
\hline \multicolumn{5}{|c|}{ Synergy index $(S)=1.82$ (95\% Cl: 0.13-24.85) } \\
\hline
\end{tabular}

* Adjusted for age, region of residence, number of children, and education.

+ Statistically significant with the $95 \% \mathrm{Cl}$ of RERI $>0$, the $95 \% \mathrm{Cl}$ of AP $>0$, or the $95 \% \mathrm{Cl}$ of $\mathrm{S}>1$, indicating additive interaction.

there were no interactions between perinatal smoking exposure and SNPs rs1800925 and rs20541 in the etiology of childhood eczema [15]. In the current study, no significant interaction was observed between SNP rs1800925 and smoking with respect to eczema.

The current study offers two main methodological advantages: study subjects were homogeneous in that they were all pregnant women, and adjustment was made for several confounders. Nevertheless, we could not rule out residual confounding because of other unknown variables. It is also subject to several limitations, however: first, the participation rate cannot be calculated because the exact number of eligible pregnant women who were provided with the abovementioned KOMCHS documents is not available. In addition, we were not able to assess differences between participants and non-participants, because information on personal characteristics such as age, socioeconomic status, and a history of allergic disorders among the non-participants was not available. Our subjects were probably not a representative sample of Japanese women in the general population; it can be shown, for example, that educational levels were higher in the current study population than in the general population. According to the 2000 population census of Japan, the proportions of women aged 30 to 34 years in Fukuoka Prefecture with years of education of $<13$, 13$14, \geq 15$, and unknown were $52.0 \%, 31.5 \%, 11.8 \%$, and $4.8 \%$, respectively [27]. The corresponding figures for the current study in the control group were $21.1 \%, 34.0 \%$, $44.9 \%$, and $0.0 \%$, respectively. Thus the present population might have had greater awareness concerning health-related matters compared to the general population. Regardless, the distribution of the 2 SNPs under study in the control group was in agreement with the Hardy-Weinberg equilibrium.

The definition of eczema was based on the questions in the ISAAC questionnaire, although validation tests of such questions have not been performed for Japanese young adults. Data on serum-specific IgE levels or skin prick tests were not available. The possibility of non-differential outcome misclassification might have biased the magnitude of the observed associations toward the null.

Control subjects were women without eczema as defined by the ISAAC criteria who had not been diagnosed by a doctor with atopic eczema and had no current asthma as defined by the European Community Respiratory Health Survey. To minimize the effect of allergic sensitization based on asthma in our cases, we performed a sensitivity analysis excluding cases with current asthma: the results of the sensitivity analysis were similar to those in the overall analysis.

The number of cases was rather small for a valid genetic association study, but a significant association with SNP rs1800925 was nevertheless detected.

Correction for multiple testing was not performed in the current study. As this is a hypothesis testing study and part of the current findings is a replication of previously published results, we think that correction for multiple testing would cause us to underestimate our results.

\section{Conclusions}

The current study suggests that IL13 SNP rs1800925, but not rs20541, is significantly associated with the risk of eczema in Japanese young adult women. To our knowledge, this is the first study to find a significant association between SNP rs1800925 and eczema in nonWestern adult populations. We could not provide evidence for an interaction between SNP rs1800925 and smoking with respect to eczema. Additional studies with a greater number of cases are required to confirm these findings.

\section{Abbreviations}

Cl: Confidence interval; ISAAC: International Study of Asthma and Allergies in Childhood; KOMCHS: Kyushu Okinawa Maternal and Child Health Study; OR: Odds ratio; SNP: single nucleotide polymorphism. 


\section{Acknowledgements}

The authors would like to thank the Kyushu Branch of the Japan Allergy Foundation, the Fukuoka Association of Obstetricians \& Gynecologists, the Okinawa Association of Obstetricians \& Gynecologists, the Miyazaki Association of Obstetricians \& Gynecologists, the Oita Association of Obstetricians \& Gynecologists, the Kumamoto Association of Obstetricians \& Gynecologists, the Nagasaki Association of Obstetricians \& Gynecologists, the Kagoshima Association of Obstetricians \& Gynecologists, the Saga Association of Obstetricians \& Gynecologists, the Fukuoka Society of Obstetrics and Gynecology, the Okinawa Society of Obstetrics and Gynecology, the Fukuoka City Government, and the Fukuoka City Medical Association for their valuable support, as well as Mrs. Yukari Hayashi for her technical assistance.

This study was supported by KAKENHI (19590606, 20791654, 21590673, and 22592355), by Health and Labour Sciences Research Grants for Research on Allergic Disease and Immunology from the Ministry of Health, Labour, and Welfare of Japan, by the Central Research Institute of Fukuoka University, and by the Takeda Science Foundation.

\section{Author details}

'Department of Preventive Medicine and Public Health, Faculty of Medicine, Fukuoka University, Fukuoka, Japan. ${ }^{2}$ Field Science for Health and Recreation, Faculty of Tourism Sciences and Industrial Management, University of the Ryukyus, Okinawa, Japan.

\section{Authors' contributions}

$\mathrm{YM}, \mathrm{KT}$, and MA contributed to the study concept and design and the acquisition of data. YM was responsible for the analysis and interpretation of data and the drafting of the manuscript. All authors participated in critically revising the manuscript and approved the final version of the manuscript

\section{Competing interests}

The authors declare that they have no competing interests.

Received: 21 April 2011 Accepted: 21 October 2011

Published: 21 October 2011

\section{References}

1. Saeki H, Oiso N, Honma M, lizuka H, Kawada A, Tamaki K: Prevalence of atopic dermatitis in Japanese adults and community validation of the $\mathrm{U}$. K. diagnostic criteria. J Dermatol Sci 2009, 55:140-141.

2. Wynn TA: IL-13 effector functions. Annu Rev Immunol 2003, 21:425-456.

3. Hamid Q, Naseer T, Minshall EM, Song YL, Boguniewicz M, Leung DY: In vivo expression of IL-12 and IL-13 in atopic dermatitis. J Allergy Clin Immunol 1996, 98:225-231.

4. Obara W, Kawa Y, Ra C, Nishioka K, Soma Y, Mizoguchi M: T cells and mast cells as a major source of interleukin-13 in atopic dermatitis. Dermatology 2002, 205:11-17.

5. La Grutta S, Richiusa P, Pizzolanti G, Mattina A, Pajno GB, Citarrella R, Passalacqua G, Giordano C: CD4 ${ }^{+} \mathrm{IL}-13^{+}$cells in peripheral blood well correlates with the severity of atopic dermatitis in children. Allergy 2005, 60:391-395.

6. Lange J, Ngoumou G, Berkenheide S, Moseler M, Mattes J, Kuehr J, Kopp MV: High interleukin-13 production by phytohaemagglutinin- and Der p 1-stimulated cord blood mononuclear cells is associated with the subsequent development of atopic dermatitis at the age of 3 years. Clin Exp Allergy 2003, 33:1537-1543.

7. Liu X, Nickel R, Beyer K, Wahn U, Ehrlich E, Freidhoff LR, Björkstén B, Beaty TH, Huang SK: An IL13 coding region variant is associated with a high total serum IgE level and atopic dermatitis in the German multicenter atopy study (MAS-90). J Allergy Clin Immunol 2000, 106:167-170

8. Tsunemi Y, Saeki H, Nakamura K, Sekiya T, Hirai K, Kakinuma T, Fujita H, Asano N, Tanida Y, Wakugawa M, Torii H, Tamaki K: Interleukin-13 gene polymorphism G4257A is associated with atopic dermatitis in Japanese patients. J Dermatol Sci 2002, 30:100-107.

9. Hummelshoj T, Bodtger U, Datta P, Malling HJ, Oturai A, Poulsen LK, Ryder LP, Sorensen PS, Svejgaard E, Svejgaard A: Association between an interleukin-13 promoter polymorphism and atopy. Eur I Immunogenet 2003, 30:355-359.
10. He JQ, Chan-Yeung M, Becker AB, Dimich-Ward H, Ferguson AC, Manfreda J, Watson WT, Sandford AJ: Genetic variants of the IL13 and IL4 genes and atopic diseases in at-risk children. Genes Immun 2003, 4:385-389.

11. Hoffjan S, Ostrovnaja I, Nicolae D, Newman DL, Nicolae R, Gangnon R, Steiner L, Walker K, Reynolds R, Greene D, Mirel D, Gern JE, Lemanske RF Jr, Ober C: Genetic variation in immunoregulatory pathways and atopic phenotypes in infancy. J Allergy Clin Immunol 2004, 113:511-518.

12. Chang YT, Lee WR, Yu CW, Liu HN, Lin MW, Huang CH, Chen CC, Lee DD, Wang WJ, Hu CH, Tsai SF: No association of cytokine gene polymorphisms in Chinese patients with atopic dermatitis. Clin Exp Dermatol 2006, 31:419-423.

13. Arshad SH, Karmaus W, Kurukulaaratchy R, Sadeghnejad A, Huebner M, Ewart S: Polymorphisms in the interleukin 13 and GATA binding protein 3 genes and the development of eczema during childhood. $\mathrm{Br} J$ Dermatol 2008, 158:1315-1322.

14. Genuneit J, Cantelmo JL, Weinmayr G, Wong GW, Cooper PJ, Riikjärv MA, Gotua M, Kabesch M, von Mutius E, Forastiere F, Crane J, Nystad W, El-Sharif N, Batlles-Garrido J, García-Marcos L, García-Hernández G, Morales-SuarezVarela M, Nilsson L, Bråbäck L, Saraçlar Y, Weiland SK, Cookson WO, Strachan D, Moffatt MF, ISAAC Phase 2 Study Group: A multi-centre study of candidate genes for wheeze and allergy: the International Study of Asthma and Allergies in Childhood Phase 2. Clin Exp Allergy 2009, 39:1875-1888.

15. Miyake Y, Kiyohara C, Koyanagi M, Fujimoto T, Shirasawa S, Tanaka K, Sasaki S, Hirota Y: Case-control study of eczema associated with IL13 genetic polymorphisms in Japanese children. Int Arch Allergy Immunol 2011, 154:328-335

16. Williams H, Robertson C, Stewart A, Aitt-Khaled N, Anabwani G, Anderson R, Asher I, Beasley R, Björkstén B, Burr M, Clayton T, Crane J, Ellwood P, Keil U, Lai C, Mallol J, Martinez F, Mitchell E, Montefort S, Pearce N, Shah J, Sibbald B, Strachan D, von Mutius E, Weiland SK: Worldwide variations in the prevalence of symptoms of atopic eczema in the international study of asthma and allergies in childhood. J Allergy Clin Immunol 1999, 103:125-138.

17. European Community Respiratory Health Survey: Variations in the prevalence of respiratory symptoms, self-reported asthma attacks, and use of asthma medication in the European Community Respiratory Health Survey (ECRHS). Eur Respir J 1996, 9:687-695.

18. Barrett JC, Fry B, Maller J, Daly MJ: Haploview: analysis and visualization of LD and haplotype maps. Bioinformatics 2005, 21:263-265.

19. Gauderman WJ: Sample size requirements for matched case-control studies of gene-environment interaction. Stat Med 2002, 21:35-50.

20. Andersson T, Alfredsson L, Källlberg H, Zdravkovic S, Ahlbom A: Calculating measures of biological interaction. Eur J Epidemiol 2005, 20:575-579.

21. Knol MJ, VanderWeele TJ, Groenwold RH, Klungel OH, Rovers MM Grobbee DE: Estimating measures of interaction on an additive scale for preventive exposures. Eur J Epidemiol 2011, 26:433-438.

22. van der Pouw Kraan TC, van Veen A, Boeije LC, van Tuyl SA, de Groot ER, Stapel SO, Bakker A, Verweij CL, Aarden LA, van der Zee JS: An IL-13 promoter polymorphism associated with increased risk of allergic asthma. Genes Immun 1999, 1:61-65.

23. Cameron L, Webster RB, Strempel JM, Kiesler P, Kabesch M Ramachandran H, Yu L, Stern DA, Graves PE, Lohman IC, Wright AL, Halonen M, Klimecki WT, Vercelli D: Th2 cell-selective enhancement of human IL13 transcription by IL13-1112C > T, a polymorphism associated with allergic inflammation. J Immunol 2006, 177:8633-8642.

24. Vladich FD, Brazille SM, Stern D, Peck ML, Ghittoni R, Vercelli D: IL-13 R130Q, a common variant associated with allergy and asthma, enhances effector mechanisms essential for human allergic inflammation. J Clin Invest 2005, 115:747-754

25. Feleszko W, Zawadzka-Krajewska A, Matysiak K, Lewandowska D, Peradzyńska J, Dinh QT, Hamelmann E, Groneberg DA, Kulus M: Parental tobacco smoking is associated with augmented IL-13 secretion in children with allergic asthma. J Allergy Clin Immunol 2006, 117:97-102.

26. Black S, Teixeira AS, Loh AX, Vinall L, Holloway JW, Hardy R, Swallow DM: Contribution of functional variation in the IL13 gene to allergy, hay fever and asthma in the NSHD longitudinal 1946 birth cohort. Allergy 2009, 64:1172-1178.

27. Statistics Bureau, Ministry of Public Management, HomeAffairs, Posts and Telecommunications: 2000 Population Census of Japan, Vol. 3-2-40, Labour 
Force Status of Population, Industry (Major Groups) of Employed Persons, and Education, Fukuoka-ken Tokyo: Statistics Bureau, Ministry of Public

Management, Home Affairs, Posts and Telecommunications; 2002, (in Japanese).

\section{Pre-publication history}

The pre-publication history for this paper can be accessed here: http://www.biomedcentral.com/1471-2350/12/142/prepub

doi:10.1186/1471-2350-12-142

Cite this article as: Miyake et al:: $1 L 13$ genetic polymorphisms, smoking, and eczema in women: a case-control study in Japan. BMC Medical

Genetics 2011 12:142

Submit your next manuscript to BioMed Central and take full advantage of:

- Convenient online submission

- Thorough peer review

- No space constraints or color figure charges

- Immediate publication on acceptance

- Inclusion in PubMed, CAS, Scopus and Google Scholar

- Research which is freely available for redistribution

Submit your manuscript at www.biomedcentral.com/submit 